\title{
Conservation genetics of extremely isolated urban populations of the Northern Dusky Salamander (Desmognathus fuscus) in New York City
}

Urbanization is a major cause of amphibian decline. Stream-dwelling plethodontid salamanders are particularly susceptible to urbanization due to declining water quality and hydrological changes, but few studies have examined these taxa in cities. The northern dusky salamander (Desmognathus fuscus) was once common in the New York City metropolitan area, but has substantially declined throughout the region in recent decades. We used five tetranucleotide microsatellite loci to examine population differentiation, genetic variation, and bottlenecks among five remnant urban populations of dusky salamanders in NYC. These genetic measures provide information on isolation, prevalence of inbreeding, long-term prospects for population persistence, and potential for evolutionary responses to future environmental change. All populations were genetically differentiated from each other, and the most isolated populations in Manhattan have maintained very little genetic variation (i.e. $<20 \%$ heterozygosity). A majority of the populations also exhibited evidence of genetic bottlenecks. These findings contrast with published estimates of high genetic variation within and lack of structure between populations of other desmognathine salamanders sampled over similar or larger spatial scales. Declines in genetic variation likely resulted from population extirpations and the degradation of stream and terrestrial paths for dispersal in NYC. Loss of genetic variability in populations isolated by human development may be an underappreciated cause and/or consequence of the decline of this species in urbanized areas of the northeast USA. 
2 Jason Munshi-South ${ }^{1,2}$, Yana Zak ${ }^{1}$ \& Ellen Pehek ${ }^{3}$

3

$4 \quad{ }^{1}$ Department of Natural Sciences, Box A-506, Baruch College, City University of New York

5 (CUNY), 17 Lexington Avenue, New York, NY 10010 USA

6

$7 \quad{ }^{2}$ Program in Ecology, Evolutionary Biology, \& Behavior, The Graduate Center, City University

8 of New York, 365 Fifth Avenue, New York, NY 10016 USA

9

$10{ }^{3}$ New York City Department of Parks and Recreation, Natural Resources Group, Urban Field

11 Station, Ft. Totten Bldg. 431, Bayside, NY 11359

12

13 Corresponding author: Jason Munshi-South

14 Department of Natural Sciences, Box A-506, Baruch College, City University of New York

15 (CUNY), 17 Lexington Avenue, New York, NY 10010 USA

16 E-mail: jason@NYCevolution.org

17 Tel: 1-646-318-6353

18 Fax: 1-646-660-6250

19 


\section{Introduction}

21 Urbanization has emerged as a substantial cause of the decline of amphibian species (Gibbs et al.

22 2005; Hamer \& McDonnell 2008). Increasing human population density produces habitat loss

23 and fragmentation that are implicated in the decline of all but a few generalist species that can

24 survive in the urban matrix. Roads alone result in increased mortality and habitat fragmentation

(Balkenhol \& Waits 2009), and are potentially potent barriers to gene flow between some amphibian populations (Emel \& Storfer 2012). Over 30 studies have been conducted on urban amphibians in North America, but research has been biased toward anuran sampling using call surveys (Scheffers \& Paszkowski 2011). Lungless salamanders (Family: Plethodontidae) are particularly understudied, despite their potential as bioindicators of habitat quality (Welsh Jr \& Droege 2001). The few plethodontid studies indicate that species richness and abundance of individual stream-dwelling species decline after urbanization (Hamer \& McDonnell 2008; Price

et al. 2011). Experimental data suggest that increased impermeable surfaces in urban watersheds result in larval salamanders being flushed out of streams at a higher rate due to increased water velocity (Barrett et al. 2010). Furthermore, riparian buffer zones provide little protection in urbanized watersheds (Willson \& Dorcas 2003). Nearly half of New York City's (NYC) native salamander species have been lost over the last century. Stream dwelling species have fared slightly better than pond breeding taxa, perhaps due to the option of dispersing through stream networks rather than overland through degraded urban matrix (Pehek 2007).

The northern dusky salamander, Desmognathus fuscus (Rafinesque 1820), persists in small, isolated streams and spring-fed seeps that have escaped development in the NYC metropolitan area. Populations in Manhattan persist in narrow, linear parklands (i.e. less than 200 m wide) on rocky hillsides surrounded by roads and urban development, whereas Staten 
43 Island and suburban New Jersey populations inhabit streams and swamps in larger protected

44 areas of secondary forest that may still be connected through stream networks. This species was

45 common in NYC as late as the 1950's (Kieran 1982), but has since declined regionally due to

46 habitat destruction and declining water quality. Population losses have also been reported from

47 large, contiguous protected areas in the northeastern USA (Bank et al. 2006), and population

48 densities of southern dusky salamanders (D. auriculatus) are inversely correlated with the degree

49 of urbanization (Orser \& Shure 1972). Population stability may be realized when salamanders

50 disperse through multiple pathways in stream networks (Campbell Grant et al. 2010), but both

51 streams (Walsh et al. 2005) and overland corridors (Munshi-South 2012) are typically degraded

52 in urban environments. Other small vertebrates with limited dispersal ability also exhibit

53 population genetic patterns consistent with loss of population connectivity.-Terrestrial

54 plethodontids (Marsh et al. 2007; Noël \& Lapointe 2010), small mammals (Munshi-South \&

55 Kharchenko 2010), birds, and lizards (Delaney et al. 2010) all exhibit substantial genetic

56 differentiation and loss of connectivityisolation among isolated urban populations.

$57 \quad$-In this study, we use five tetranucleotide microsatellite loci to examine genetic diversity

58 and differentiation among northern dusky salementer fuscus populations inhabiting isolated

59 streams in NYC. We sampled all known locations in NYC and contiguous suburban counties to

60 provide context on the genetic relationships between NYC populations and surrounding regions.

61 D. fuscus populations in NYC are well-known to the local human communities surrounding their

62 stream habitats, and are a species of interest for conservation efforts in northern Manhattan and

63 the Staten Island Greenbelt watershed. While these salamanders have persisted for decades in

64 the same highly urbanized locations (Gans 1945), loss of genetic variation due to inbreeding and

65 isolation are unknown. - Due to its regional population decline, degradation of stream networks, 
66 and sensitivity to urban water quality, we predicted that $D$. fuscus exhibits even greater genetic impacts from urbanization than other small vertebrates with limited mobility. Under this scenario, remnant $D$. fuscus populations may require conservation efforts to restore connectivity between populations or translocations to counteract inbreeding depression. This study is the first to our knowledge to investigate the conservation genetics of urban stream salamanders, and the results will be applied to future amphibian conservation decisions concerning amphibian reintroductions, watershed management, and landscape planning for biodiversity in NYC.

\section{Methods}

75 Sampling was conducted in 2010-2011 at five sites known to harbor dusky salamanders (Figure

76 1): two seepage areas in Highbridge Park, Manhattan, NYC; streams in Corson’s Brook Woods

77 and Reed's Basket Willow Swamp Park in Staten Island, NYC; and a stream in the Watchung Reservation, Union Co., NJ, approximately 48 km west of NYC. These sites were sampled because they were the only sites known to contain $D$. fuscus in NYC or adjacent suburban counties, and the NYC sites are managed by the NYC Department of Parks \& Recreation as

81 "Forever Wild” conservation areas. The Highbridge Park sites were rediscovered by one of the 82 authors (EP) in 2005 based on a note in the herpetological literature (Gans 1945). These two 83 seeps are isolated from each other by the Washington and Hamilton Bridges (erected in 1888 and 1963, respectively) that cumulatively carry fourteen lanes of automobile traffic. The Staten Island sites are part of the Greenbelt, a contiguous series of protected areas totaling 1,100 ha composed of swamps and secondary forests. The Watchung Reservation in NJ is a 790 ha protected area composed of primary forest and recreational areas in a valley of the Watchung mountains, and is surrounded by low- to medium-density suburban housing. -We also searched 
89 for but were unable to locate $D$. fuscus at other locations where they have been reported in recent

90 decades, including the Lost Brook Preserve in the Palisades, NJ, and two sites in Westchester

91 Co., NY: Hilltop Hanover Farms and Ward Pound Ridge Reservation. We initially also failed to

92 sample D. fuscus from the Great Swamp at the Greenbelt Nature Center, Staten Island, NY, but

93 did find a few individuals after the sampling and lab work for this study were concluded. These

94 samples and another site recently discovered on Staten Island (Bloodroot Valley) will be included

95 in a future landscape genomics study of urban salamanders (see Discussion).

96 We captured salamanders by hand or dipnet after turning over cover objects such as logs,

97 rocks, bottles, and metal / plastic sheeting in or near streams. Tail tips were clipped and stored in

98 80\% ethanol until DNA extraction using the standard protocol for the Qiagen DNEasy tissue kit.

99 All animal handling protocols were approved by the Natural Resources Group of the NYC

100 Department of Parks and Recreation, and followed the recommendations of the Declining

101 Amphibian Task Force’s "Fieldwork Code of Practice"

102 (http://www.fws.gov/ventura/species information/protocols guidelines/docs/DAFTA.pdf) and

103 the NY State Department of Environmental Conservation's “Bio-safety Protocols for Reptile and

104 Amphibian Sampling”. Five previously described microsatellite loci were PCR-amplified in 15

$105 \mu \mathrm{l}$ volumes using Promega PCR master mix and published thermal cycling profiles. PCR

106 included one primer with a CAG or M13R tail and an associated probe with fluorescent

107 WellRED D2, D3, or D4 dye. The total reaction included $7.5 \mu \mathrm{l}$ master mix, $4.4 \mu \mathrm{l}$ water, $0.8 \mu \mathrm{l}$

108 of the $10 \mu \mathrm{M}$ untailed primer, and $0.4 \mu \mathrm{l}$ each of the $10 \mu \mathrm{M}$ tailed primer and $10 \mu \mathrm{M}$ fluorescent

109 probe. The amplified loci included Dau3, Dau11, and Dau12 from Croshaw and Glenn (2003),

110 Doc03 from Adams et al. (2005), and ENS6 from Devitt et al. (2009). PCR fragments were

111 separated and sized on a Beckman Coulter CEQ8000 sequencer. Alleles were scored using 
112 automatic binning procedures followed by visual inspection in the Beckman fragment analysis

113 software. The genotypes and spatial coordinates for all study sites are available on the Dryad

114 digital repository (doi: XXXXXXX).

115 Each locus was tested for deviations from Hardy-Weinberg (HWE) and linkage

116 equilibrium over the total sample of 141 genotypes and within each of the five sampling sites

117 using GENEPOP 4.0 (Rousset 2008). We also used MICRO-CHECKER to analyze genotypes

118 within each population for homozygote excess due to null alleles, allelic dropout, or errors in

119 allele calling due to stuttering (van Oosterhout et al. 2004). To characterize genetic diversity, we

120 calculated the numbers of alleles, effective alleles, and private alleles at each site, and the

121 observed and expected heterozygosity at each site and for each locus across the entire sample,

122 using GenAlex 6.4 (Peakall \& Smouse 2005). We tested for genetic bottlenecks in each

123 population using the authors' recommended settings for microsatellites (TPM; 95\% single-step

124 mutations) in BOTTLENECK 1.2 (Piry et al. 1999).

125 To examine population differentiation, we calculated pairwise $F_{\text {ST }}$ between all site pairs

126 using 1,000 random permutations in GenAlex to assess significance. We then used the

127 evolutionary clustering method implemented in STRUCTURE 2.3 to place individual genotypes

128 in clusters that minimized deviations from Hardy-Weinberg and linkage equilibria (Pritchard et

129 al. 2000). We did not use the sampling site as prior information, and allowed for correlated

130 allele frequencies and genetic admixture across populations (Falush et al. 2003). We conducted

131 ten replicate runs for each value of $K=1 \_-10$, with a burn-in of 500,000 followed by 4.5 million

132 iterations. The most likely $K$ was identified using the mean and standard deviation of $\operatorname{Pr}(\mathrm{X} \mid K)$,

133 and the $\Delta K$ method from Evanno et al. (2005), as calculated by the STRUCTURE HARVESTER

134 (Earl \& vonHoldt 2011). We used CLUMPP 1.1 (Jakobsson \& Rosenberg 2007) and 
135 DISTRUCT 1.1 (Rosenberg 2004) to align and visualize the results of the ten replicates at the

136 most likely value of $K$. We also used the 'spatial clustering of groups' module in BAPS 5.2 to

137 identify the best value of $K$ using predefined sampling sites and spatial coordinates as prior

138 information (Corander et al. 2008).

\section{Results \& Discussion}

141 All loci were in linkage equilibrium across the entire dataset and within each population.

142 However, all loci deviated from HWE across the entire dataset (Table 1), most likely due to a

143 Wahlund effect resulting from population structure. Most loci within sites were in HWE except

144 for three loci in Highbridge Park South (Table 2). Loci within each population exhibited no

145 evidence of homozygote excess in MICROCHECKER due to microsatellite errors, with the 146 exception of two markers in the Highbridge Park South population that were positive for null

147 alleles (Doc03 and Ens06).

148 Heterozygosity was moderately low for the NJ and Staten Island sites $\left(\mathrm{H}_{\mathrm{O}}=0.40-0.57\right)$,

149 but considerably lower for both north $\left(\mathrm{H}_{\mathrm{O}}=0.14\right)$ and south $\left(\mathrm{H}_{\mathrm{O}}=0.29\right)$ Highbridge Park in

150 Manhattan (Table 2). We found evidence of genetic bottlenecks for both Highbridge sites and

151 the Watchung Reservation, but not the Staten Island populations. These populations all exhibited

152 substantially lower heterozygosity at the same loci as than D. auriculatus $\left(\underline{H}_{0}=0.63-0.94\right.$;

153 Croshaw \& Glenn 2003) and D. ocoee ( $\underline{\mathrm{H}}_{\mathrm{O}}=0.95$; Adams et al. 2005) sampled from non-urban

154 streams. Five microsatellite markers are predicted to have sufficient power for detecting only

155 moderate to severe bottlenecks, but the variability of tetranucleotide microsatellites and

156 relatively large number of individuals sampled from each population somewhat offset concerns

157 over the number of loci (Cornuet \& Luikart 1996). Substantial population bottlenecks are 
158 plausible demographic scenarios for the Manhattan populations given that they inhabit two tiny

159 seeps in a degraded urban secondary forest, and dusky salamanders do not occur elsewhere in

160 Manhattan or even in neighboring counties on different landmasses. The Watchung Reservation

161 population occurs in a relatively large, contiguous protected area, but $D$. fuscus may be confined

162 to a single stream there and no known extant populations exist nearby. Larger protected areas,

163 population sizes, and the potential ability to disperse through stream networks may have

164 prevented substantial demographic decline in Staten Island populations.

165 Highbridge South had more than twice the number of private alleles compared to the

166 other sites, and double the heterozygosity of Highbridge North (Table 2). Coupled with three

167 loci out of Hardy-Weinberg, it is possible that Highbridge South receives migrants or contains

168 ancestral variation from unknown seeps in the park. The possibility of human translocations also

169 cannot be completely ruled out in a dense urban environment where these salamanders are

170 well-known to the local human population. The MICROCHECKER results indicated a low but

171 detectable frequency of null alleles at this site, suggesting the occurrence of mutations in the

172 flanking sequence for two of the microsatellite loci. Highbridge North exhibits the lowest

173 genetic diversity in NYC with most alleles nearing fixation, and may have experienced a much

174 more severe population bottleneck than other populations. Long-term mark-recapture studies are needed to determine whether these populations are declining due to inbreeding depression. -

Transect-Occasional population ssurveys conducted over the last seven years indicate that both of these sites harbor relatively high population densitiesdozens to hundreds of individuals with a broad range of body sizes (E. Pehek, unpublished data),, but lack of connectivity with any other 
181

182

183

184

185

186

187

188

189

190

191

192

\section{3}

194

195

196

198

199

200

201

202

203

imminent extinction due to demographic factors. However, lack of connectivity with any other populations has likely resulted in strong genetic drift and loss of variation over the last several dozens of generations.

Pairwise $F_{\text {ST }}$ was significant for all population pairs, and ranged from 0.08 between the two Highbridge sites to 0.51 between Highbridge North and Reed’s Basket Willow (Table 3). All pairwise values were greater than 0.2 except for $F_{\text {ST }}$ between the two Highbridge sites. The Highbridge sites exhibited greater genetic differentiation from the three Staten Island / NJ sites than any of the Staten Island / NJ sites from each other. These results suggest that Highbridge Park contains the most isolated populations of dusky salamanders in the NYC region. Clustering analysis in STRUCTURE indicated that all but the two Highbridge sites contain genetically differentiated populations of dusky salamanders. The highest probability of the data, $\operatorname{Pr}(\mathrm{X} \mid K)$, was calculated for $K=6$, and the value of $\Delta K$ was highest at $K=2$. The bar plot for $K=6$ indicates substantial admixture between the two Highbridge sites but unique evolutionary clusters present in the three other Staten Island / NJ sites (Figure 2). The $K=2$ bar plot captures the divergence between Manhattan and the Staten Island / NJ sites, which likely predates urbanization due to the presence of these populations on different landmasses. Individuals with relatively unique genotypes were also present in Highbridge South, most likely due to the high number of private alleles. Given the heterozygosity results above, $D$. fuscus in North Highbridge contain only a small subset of the genetic variation found south of the two bridges dividing the park. The BAPS analysis identified all five sampling sites as unique evolutionary clusters (posterior probability = 0.999; Figure 2), $=$ This latter result indicatesindieating that the north and south populations of Highbridge Park are moderately differentiated potentially due to the bridges separating them. 
Our results indicate that isolated urban populations of stream salamanders in NYC

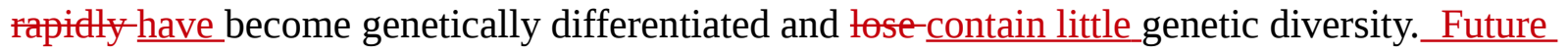
work will be needed to determine whether these patterns occurred due to urbanization of NYC over the last 200 years, or predate the formation of the city. Extremely low variability for a pair

of Manhattan sites separated by two bridges likely reflects an earlier or more severe isolation

than for the other sites. A moderate $F_{\mathrm{ST}}$ between the two Manhattan sites, and several private alleles in the area south of two bridges that bisect Highbridge parkPark, indicate that urban infrastructure can create near-total isolation between proximal stream salamander populations. Heterozygosity was not as low in Staten Island, perhaps because these populations have not experienced recent bottlenecks and reside in a much larger system of protected areas with higher-order streamsand have not experiened reent bottlenecks. Improvements in water quality $y_{2}$ and removal of within-stream and overland barriers could potentially increase dusky salamander habitat in Staten Island, although few opportunities would exist for such actions in Manhattan. Restoration of connectivity in Staten Island could also take the form of culverts under roads, "daylighting" of streams that currently flow underground due to development, and removal of stream impoundments. - Reintroductions from larger populations distant from the urban core eothtmay also improve the long-term prospects for these Staten Island populations. However, disease screening (i.e. amphibian chytrid fungus) and further genetic analysis should 222 be conducted on potential source populations before any reintroductions are attempted on Staten 223 Island, as pairwise $F_{\text {ST }}$ values were relatively high even between populations on the island. The 224 recent discovery of a new species of leopard frog on Staten Island also raises the possibility of 225 previously underappreciated phylogeographic structure or centers of endemism for amphibians in 226 the NYC metropolitan area (Newman et al. 2012). 

pairwise $F_{\mathrm{ST}}$, but a similar heterozygosity, to values reported in this study for Staten Island and NJ ( $\underline{H}_{\mathrm{O}}=0.34-0.51$; Noël \& Lapointe 2010). However, these authors focused on a terrestrial species, Plethodon cinereus, in Montréal that can persist in even the smallest woodlots; other genetic results indicate that this species is unaffected by all but the largest roadways (Marsh et al. 2007). P. cinereus occurs in many NYC parks, community gardens, and other semi-natural spaces, suggesting that it is less strongly affected by urban fragmentation (Pehek 2007). The northern two-lined salamander, Eurycea bislineata, is a stream-dwelling species occupying a greater number of sites in NYC than $D$. fuscus, and thus may fall somewhere between $P$. cinereus and $D$. fuscus in maintaining heterozygosity in isolated urban fragments. We are currently examining E. bislineata, as well as reassessing $D$. fuscus, in NYC using high-density SNP (single nucleotide polymorphism) genotypes. particularly on stream salamanders, but a recent meta-analysis reported that species with an IUCN status of “Least Concern” exhibited generally lower $F_{\text {ST }}$ values than species in more threatened categories (Emel \& Storfer 2012). The authors interpreted this trend as suggestive of population extirpation in fragmented habitats as species first become threatened. Such a scenario

244 would seem to apply to $D$. fuscus in urban and suburban habitats as most populations in the NYC 245 metro area have disappeared, and the results here demonstrate substantial genetic differentiation 246 between the extant populations.

247 Desmognathine salamanders have been the subject of many phylogeographic and 248 molecular systematic analyses due to their high diversity in Appalachia (Bonett 2002; Crespi et 249 al. 2003; Rissler \& Taylor 2003; Tilley et al. 2008; Beamer \& Lamb 2008), but there are only a 
250 few published population genetic analyses available to place the results of this study in context.

251 Rissler et al. (2004) found little genetic structure between populations of D. monticola in

252 different river drainages, and Croshaw \& Glenn (2003) reported two- to four-fold higher

253 heterozygosity in a D. auriculatus population compared to the results presented here. An

254 Appalachian endemic with a highly restricted range, $D$. folkertsi, also exhibited very little genetic

255 structure across river drainages, although this result may be partly explained by human transport

256 of these salamanders between sites (Wooten et al. 2010). These results indicate that the low

257 levels of genetic variability and substantial genetic structure between $D$. fuscus populations in

258 NYC are not typical of the genus.

259

Gene flow in non-desmognathine stream salamanders is maintained by dispersal through

260 stream networks in relatively undisturbed areas, although not necessarily everywhere in a

261 species' range (Trumbo et al. 2013). Gene flow also occurs along stream channels within the

262 same catchments for some taxa, although there may be directional bias (Lowe et al. 2008) or

263 significant genetic differentiation between populations in different catchments or river basins

264 (Mullen et al. 2010). In contrast, levels of genetic divergence similar to those reported here may

265 be natural features of some salamander species. $F_{\text {ST }}$ values from $0.14=-0.57$ have been reported

266 for high elevation taxa exhibiting philopatry to breeding ponds (Savage et al. 2010) or river

267 drainages (Mila et al. 2010). Genetic isolation is also characteristic of isolated, spring-associated

268 Eurycea populations that cannot disperse through underground aquifers or streams (Lucas et al.

269 2008).

270 Urban populations of other small vertebrates with limited dispersal ability exhibit

271 significant population structure, but not to the same degree as urban $D$. fuscus. White-footed

272 mice (Peromyscus leucopus) sampled from 14 urban parks in NYC showed a high degree of 
273 genetic differentiation between parks, but the $F_{\text {ST }}$ values were on the lower order of that

274 estimated between the two Manhattan D. fuscus populations in Highbridge park (Munshi-South

275 \& Kharchenko 2010). White-footed mice maintain high population densities and much higher

276 genetic variation than $D$. fuscus in $\mathrm{NYC}\left(\mathrm{H}_{\mathrm{O}}=0.63-0.82\right)$, and vegetated urban corridors do

277 allow for weak to moderate gene flow (Munshi-South 2012). Urban populations of one

278 passerine bird and three lizards exhibited significant genetic structure, but the $F_{\mathrm{ST}}$ values were in

279 line with those reported for white-footed mice rather than dusky salamanders in NYC (Delaney

280 et al. 2010). Other studies of small passerine birds have also reported weak to moderate genetic

281 structure among urban populations, but without evidence of severe loss of genetic variation

282 (Bjorklund et al. 2010; Vangestel et al. 2011; Unfried et al. 2013).

NYC’s dusky salamanders exhibit unusually low genetic variability and substantial

284 genetic structure compared to desmognathines and other species in urban environments.

285 However, this study could not determine the time since population divergence or bottlenecks to

286 rule out the possibility that these genetic phenomena occurred before urbanization of the NYC

287 area. Many salamanders including $D$. fuscus have large genomes (Wake 2009), and more than

288 five unlinked, genome-wide markers will be needed to estimate the timing of demographic

events in urban populations with precision and accuracy.__Fortmately, newe are currently

290

using reduced representation, next-generation sequencing approaches to methods-generatefor

291

generating high-density, genome-wide marker $\underline{\mathrm{SNP}}$ genotypes sets using next-generation-

292

sequeneing (Davey et al. 2011; Peterson et al. 2012) for hundreds of individuals of two species

of stream salamander in urban NYC and suburban / rural watersheds: D. fuscus and the northern

two-lined salamander, Eurycea bislineata. ,-We will then use landscape genomic approaches to 
also use and-new statistical approaches to estimating population history from genetic data

(Cornuet et al. 2010) will advance salamander conservation geneties in the near futureto examine

the timing of divergence of stream salamander populations in relation to historical information

299

on urbanization of NYC. Such approaches will also increase our ability to examine natural

selection in urban salamander populations. Although lack of genetic variation and severe genetic

drift may counteract the effects of selection in some isolated populations, urban environmental

302

conditions exert potent selective pressure on salamanders (Brady 2012) and selection itself

contributes to microgeographic divergence (Richardson \& Urban 2013). Selection favoring

philopatry, relaxed anti-predator behavior, and larger body size are all possibilities in isolated

urban seeps and streams that contain few predators or interspecific competitors, but are surrounded by hostile urban landscapes. and our results indicate that urban fragmentation results in substantial loss of genetic variability.

309 The full importance of genetic variability and inbreeding for extinction risk are still unknown,

310 but they are clearly of concern for remnant populations such as those under investigation here.

311 Although not endangered, $D$. fuscus have undoubtedly declined throughout their range in eastern

312 North America where urbanization dominates the landscape (Lannoo 2005). Loss of genetic

313 variability in populations isolated by human development may be an underappreciated cause

314 and/or consequence of their continued declines:-

316 Acknowledgments

317 We thank S.E. Harris, D. Jacob, B. Simmons, and S. Stanley for assistance in the field or

318 laboratory, and B. Kajdacsi for helpful comments on the manuscript. The NJ Department of 
319 Environmental Protection - Division of Fish \& Wildlife (Permit \#SC2010130), the Watchung

320 Reservation, and the NY State Department of Environmental Conservation (License to Collect \&

321 Possess Wildlife \#1273) provided permission to collect samples.

322

323 Funding Statement

324 This research was supported by National Science Foundation grant DEB-0817259 to Jason

325 Munshi-South.

326

327

\section{References}

328 Adams E, Jones A, Arnold S (2005) Multiple paternity in a natural population of a salamander with long-term sperm storage. Molecular Ecology, 14, 1803-1810.

Balkenhol N, Waits L (2009) Molecular road ecology: exploring the potential of genetics for investigating transportation impacts on wildlife. Molecular Ecology, 18, 4151-4164.

332

333

334

335

336

337

338

339

340

Bank M, Crocker J, Davis S, Brotherton D, et al. (2006) Population decline of northern dusky salamanders at Acadia National Park, Maine, USA. Biological Conservation, 130, 230-238.

Barrett K, Helms BS, Guyer C, Schoonover JE (2010) Linking process to pattern: Causes of stream-breeding amphibian decline in urbanized watersheds. Biological Conservation, 143, 1998-2005.

Beamer D, Lamb T (2008) Dusky salamanders (Desmognathus, Plethodontidae) from the Coastal Plain: Multiple independent lineages and their bearing on the molecular phylogeny of the genus. Molecular Phylogenetics and Evolution, 47, 143-153. 
341 Bjorklund M, Ruiz I, Senar J (2010) Genetic differentiation in the urban habitat: the great tits

342 (Parus major) of the parks of Barcelona city. Biological Journal of the Linnean Society, 99, 9-19.

344 Bonett R (2002) Analysis of the contact zone between the dusky salamanders Desmograthus fuscus fuscus and Desmognathus fuscus conanti (Caudata : Plethodontidae). Copeia, 344-355.

Brady SP (2012) Road to evolution? Local adaptation to road adjacency in an amphibian (Ambystoma maculatum). Scientific Reports, 2, 235.

Campbell Grant EH, Nichols JD, Lowe WH, Fagan WF (2010) Use of multiple dispersal pathways facilitates amphibian persistence in stream networks. Proceedings of the National Academy of Sciences, 107, 6936-6940.

Corander J, Sirén J, Arjas E (2008) Bayesian spatial modeling of genetic population structure. Computational Statistics, 23, 111-129.

Cornuet JM, Luikart G (1996) Description and Power Analysis of Two Tests for Detecting Recent Population Bottlenecks From Allele Frequency Data. Genetics, 144, 2001 -2014. using DNA sequence and microsatellite data with the software DIYABC (v1.0). BMC Bioinformatics, 11, 401. 
359 Crespi E, Rissler L, Browne R (2003) Testing Pleistocene refugia theory: phylogeographical

360 analysis of Desmognathus wrighti, a high-elevation salamander in the southern

$361 \quad$ Appalachians. Molecular Ecology, 12, 969-984.

362 Croshaw D, Glenn T (2003) Polymorphic tetranucleotide microsatellite DNA loci from the 363 southern dusky salamander (Desmognathus auriculatus). Molecular Ecology Notes, 3, $364 \quad 623-625$.

365 Davey JW, Hohenlohe PA, Etter PD, Boone JQ, et al. (2011) Genome-wide genetic marker 366 discovery and genotyping using next-generation sequencing. Nature Reviews Genetics, $367 \quad$ 12, 499-510.

368

369

370

371

372

373

374

375

376

377

378

Delaney KS, Riley SPD, Fisher RN (2010) A Rapid, Strong, and Convergent Genetic Response to Urban Habitat Fragmentation in Four Divergent and Widespread Vertebrates. PLoS ONE, 5, e12767.

Devitt TJ, Pereira R, Jakkula L, Alexandrino J, et al. (2009) Isolation and characterization of 15 polymorphic microsatellites in the Plethodontid salamander Ensatina eschscholtzii. Molecular Ecology Resources, 9, 966-969.

Earl DA, vonHoldt BM (2011) STRUCTURE HARVESTER: a website and program for visualizing STRUCTURE output and implementing the Evanno method. Conservation Genetics Resources, 4, 359-361.

Emel S, Storfer A (2012) A decade of amphibian population genetic studies: synthesis and recommendations. Conservation Genetics, 13, 1685-1689. 
379 Evanno G, Regnaut S, Goudet J (2005) Detecting the number of clusters of individuals using the software STRUCTURE: a simulation study. Molecular Ecology, 14, 2611-2620.

381 Falush D, Stephens M, Pritchard JK (2003) Inference of population structure using multilocus 382 genotype data: linked loci and correlated allele frequencies. Genetics, 164, 1567-1587.

383 Gans C (1945) Occurrence of the dusky salamander on Manhattan. Copeia, 2, 118.

384 Gibbs JP, Whiteleather KK, Schueler FW (2005) Changes in frog and toad populations over 30 385 years in New York State. Ecological Applications, 15, 1148-1157.

386 Hamer AJ, McDonnell MJ (2008) Amphibian ecology and conservation in the urbanising world: a review. Biological Conservation, 141, 2432-2449.

Homer C, Huang C, Yang L, Wylie B, et al. (2004) Development of a 2001 national landcover database for the United States. Photogrammetric Engineering and Remote Sensing, 70, 829-840.

Jakobsson M, Rosenberg NA (2007) CLUMPP: a cluster matching and permutation program for dealing with label switching and multimodality in analysis of population structure. Bioinformatics, 23, 1801-1806.

Kieran J (1982) A natural history of New York City: a personal report after fifty years of study \& enjoyment of wildlife within the boundaries of Greater New York. Fordham Univ Press. 
398 Lowe W, Mcpeek M, Likens G, Cosentino B (2008) Linking movement behaviour to dispersal 399 and divergence in plethodontid salamanders. Molecular Ecology, 17, 4459-4469.

400 Lucas LK, Gompert Z, Ott JR, Nice CC (2008) Geographic and genetic isolation in 401 spring-associated Eurycea salamanders endemic to the Edwards Plateau region of Texas. 402 Conservation Genetics, 10, 1309-1319.

403 Marsh DM, Page RB, Hanlon TJ, Corritone R, et al. (2007) Effects of roads on patterns of 404 genetic differentiation in red-backed salamanders, Plethodon cinereus. Conservation $405 \quad$ Genetics, 9, 603-613.

406 Mila B, Carranza S, Guillaume O, Clobert J (2010) Marked genetic structuring and extreme dispersal limitation in the Pyrenean brook newt Calotriton asper (Amphibia: Salamandridae) revealed by genome-wide AFLP but not mtDNA. Molecular Ecology, 19, $108-120$.

Mullen LB, Arthur Woods H, Schwartz MK, Sepulveda AJ, et al. (2010) Scale-dependent genetic structure of the Idaho giant salamander (Dicamptodon aterrimus) in stream networks. Molecular Ecology, 19, 898-909.

413 Munshi-South J, Kharchenko K (2010) Rapid, pervasive genetic differentiation of urban 414 white-footed mouse (Peromyscus leucopus) populations in New York City. Molecular 415 Ecology, 19, 4242-4254.

416 Munshi-South J (2012) Urban landscape genetics: canopy cover predicts gene flow between 417 white-footed mouse (Peromyscus leucopus) populations in New York City. Molecular

$418 \quad$ Ecology, 21, 1360-1378. 
419 Newman CE, Feinberg JA, Rissler LJ, Burger J, et al. (2012) A new species of leopard frog

420 (Anura: Ranidae) from the urban northeastern US. Molecular Phylogenetics and

$421 \quad$ Evolution, 63, 445-455.

422 Noël S, Lapointe F-J (2010) Urban conservation genetics: Study of a terrestrial salamander in the 423 city. Biological Conservation, 143, 2823-2831.

424 van Oosterhout C, Hutchinson WF, Wills DPM, Shipley P (2004) micro-checker: software for 425 identifying and correcting genotyping errors in microsatellite data. Molecular Ecology $426 \quad$ Notes, $\mathbf{4}, 535-538$.

427 Orser PN, Shure DJ (1972) Effects of urbanization on the salamander Desmognathus fuscus $428 \quad$ fuscus. Ecology, 53, 1148-1154.

429 Peakall ROD, Smouse PE (2005) GENALEX 6: genetic analysis in Excel. Population genetic 430 software for teaching and research. Molecular Ecology Notes, 6, 288-295.

431 Pehek E (2007) Salamander Diversity and Distribution in New York City, 1820 to the Present. 432 Natural History of New York City's Parks and Great Gull Island: Transactions of the 433 Linnaean Society of New York, 10, 157-182.

434 Peterson BK, Weber JN, Kay EH, Fisher HS, et al. (2012) Double Digest RADseq: An 435 Inexpensive Method for De Novo SNP Discovery and Genotyping in Model and $436 \quad$ Non-Model Species. PLoS ONE, 7, e37135. 
437 Piry S, Luikart G, Cornuet J-M (1999) BOTTLENECK: A Computer Program for Detecting

438 Recent Reductions in the Effective Size Using Allele Frequency Data. Journal of

439 Heredity, 90, 502-503.

440 Price SJ, Cecala KK, Browne RA, Dorcas ME (2011) Effects of urbanization on occupancy of 441 stream salamanders. Conservation Biology, 25, 547-555.

442 Pritchard J, Stephens M, Donnelly P (2000) Inference of population structure using multilocus 443 genotype data. Genetics, 155, 945-959.

444 Rafinesque C (1820) Annual synopsis of new genera and species of animals and plants 445 discovered in North America. Annals of Nature, 1, 1-20.

446 Richardson JL, Urban MC (2013) Strong Selection Barriers Explain Microgeographic Adaptation in Wild Salamander Populations. Evolution, in press.

448

449

450 451

452

453 454

455 456

Rissler L, Taylor D (2003) The phylogenetics of Desmognathine salamander populations across the southern Appalachians. Molecular Phylogenetics and Evolution, 27, 197-211.

Rissler L, Wilbur H, Taylor D (2004) The influence of ecology and genetics on behavioral variation in salamander populations across the Eastern Continental Divide. American Naturalist, 164, 201-213.

Rosenberg NA (2004) DISTRUCT: a program for the graphical display of population structure. Molecular Ecology Notes, 4, 137-138.

Rousset FC. (2008) Genepop’007: a complete re-implementation of the genepop software for Windows and Linux. Molecular Ecology Resources, 8, 103-106. 
457 Savage W, Fremier A, Shaffer H (2010) Landscape genetics of alpine Sierra Nevada salamanders reveal extreme population subdivision in space and time. Molecular Ecology, 19,

459 $3301-3314$

460

461

462

463

464

465

466

467

468

469

470

471

472

473

474

Scheffers BR, Paszkowski CA (2011) The effects of urbanization on North American amphibian species: Identifying new directions for urban conservation. Urban Ecosystems, 15, 133-147.

Tilley S, Eriksen R, Katz L (2008) Systematics of dusky salamanders, Desmognathus (Caudata : Plethodontidae), in the mountain and Piedmont regions of Virginia and North Carolina, USA. Zoological Journal of the Linnean Society, 152, 115-130.

Trumbo DR, Spear SF, Baumsteiger J, Storfer A (2013) Rangewide landscape genetics of an endemic Pacific northwestern salamander. Molecular Ecology, n/a-n/a.

Unfried TM, Hauser L, Marzluff JM (2013) Effects of urbanization on Song Sparrow (Melospiza melodia) population connectivity. Conservation Genetics, 14, 41-53.

Vangestel C, Mergeay J, Dawson DA, Vandomme V, et al. (2011) Spatial heterogeneity in genetic relatedness among house sparrows along an urban-rural gradient as revealed by individual-based analysis. Molecular Ecology, 20, 4643-4653.

Wake DB (2009) What salamanders have taught us about evolution. Annual Review of Ecology and Systematics, 40, 333-352. 
475 Walsh CJ, Roy AH, Feminella JW, Cottingham PD, et al. (2005) The urban stream syndrome:

476 current knowledge and the search for a cure. Journal of the North American

477 Benthological Society, 24, 706-723.

478 Welsh Jr HH, Droege S (2001) A case for using plethodontid salamanders for monitoring

480 biodiversity and ecosystem integrity of North American forests. Conservation Biology, 15, 558-569.

481

Willson J, Dorcas M (2003) Effects of habitat disturbance on stream salamanders: Implications

482 for buffer zones and watershed management. Conservation Biology, 17, 763-771.

483 Wooten JA, Camp CD, Rissler LJ (2010) Genetic diversity in a narrowly endemic, recently described dusky salamander, Desmognathus folkertsi, from the southern Appalachian Mountains. Conservation Genetics, 11, 835-854. 
490 Fig. 1 Map of study sites in relation to urbanization in the NYC metropolitan area. Areas

491 colored in shades of red and purple denote landscape areas with increasingly greater percentages

492 of impervious surfaces as measured by the 2006 National Landcover Database (Homer et al.

493 2004).

494

495 Fig. 2 Results of evolutionary clustering analyses. A) bar plots from STRUCTURE analysis for 496 estimated number of clusters $K=2$ (top) and $K=6$ (bottom). Sample sizes, $N$, appear on top of 497 each sampling site. B) Results of spatial clustering of groups in BAPS for $K=5$. The X and Y axes represent geographic coordinates of the sampling sites. WR = Watchung Reservation, CPW $=$ Corson's Brook Woods, $\mathrm{RB}=$ Reed's Basket Willow, HPS $=$ South Highbridge Park, HPN = 


\section{Figure 1}

Map of study sites

Map of study sites in relation to urbanization in the NYC metropolitan area. Areas colored in shades of red and purple denote landscape areas with increasingly greater percentages of impervious surfaces as measured by the 2006 National Landcover Database (Homer et al. 2004) . 


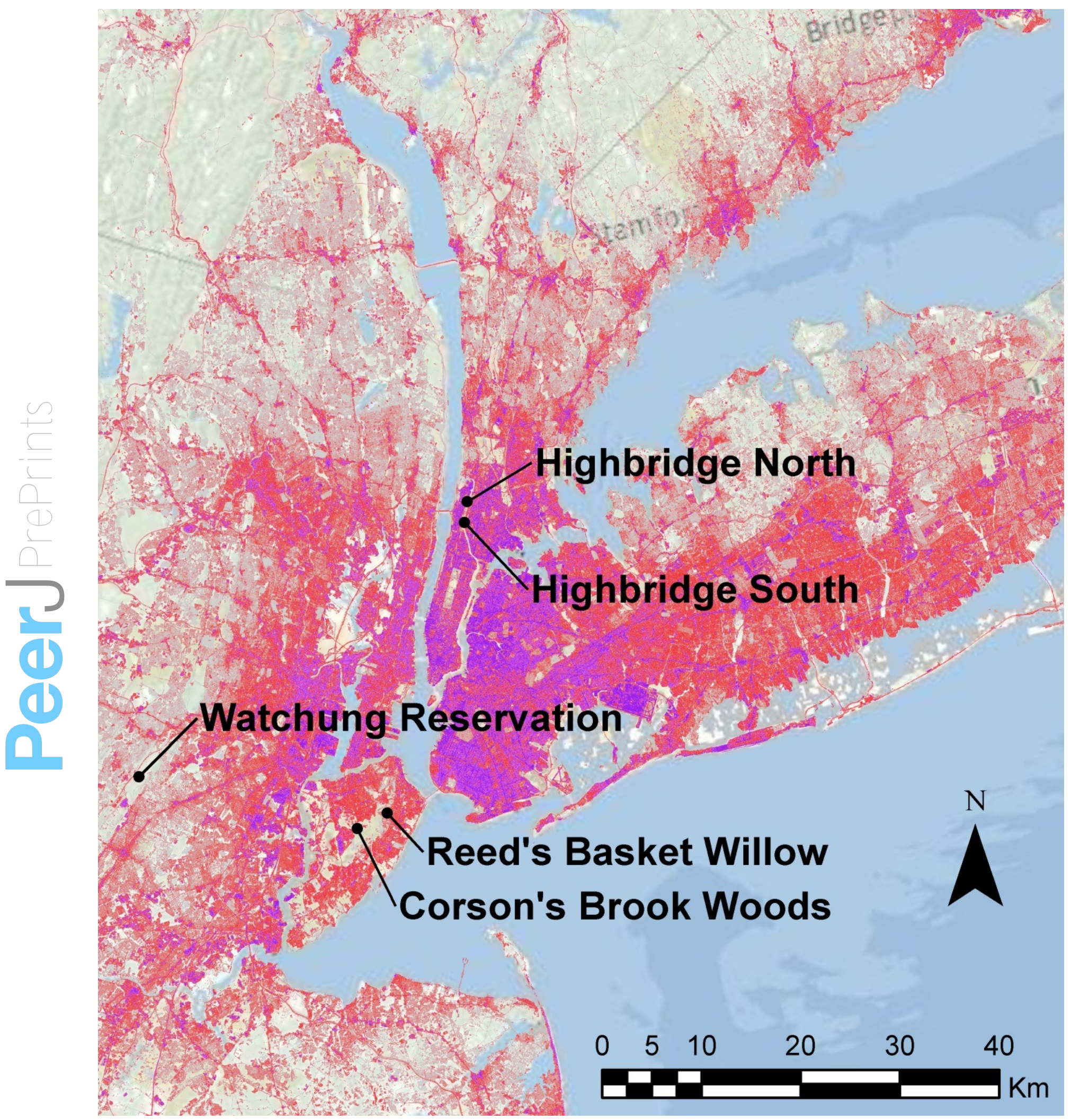




\section{Figure 2}

Results of evolutionary clustering analyses

Results of evolutionary clustering analyses. A) bar plots from STRUCTURE analysis for estimated number of clusters $K=2$ (top) and $K=6$ (bottom). Sample sizes, $N$, appear on top of each sampling site. B) Results of spatial clustering of groups in BAPS for $K=5$. The $\mathrm{X}$ and $\mathrm{Y}$ axes represent geographic coordinates of the sampling sites. 

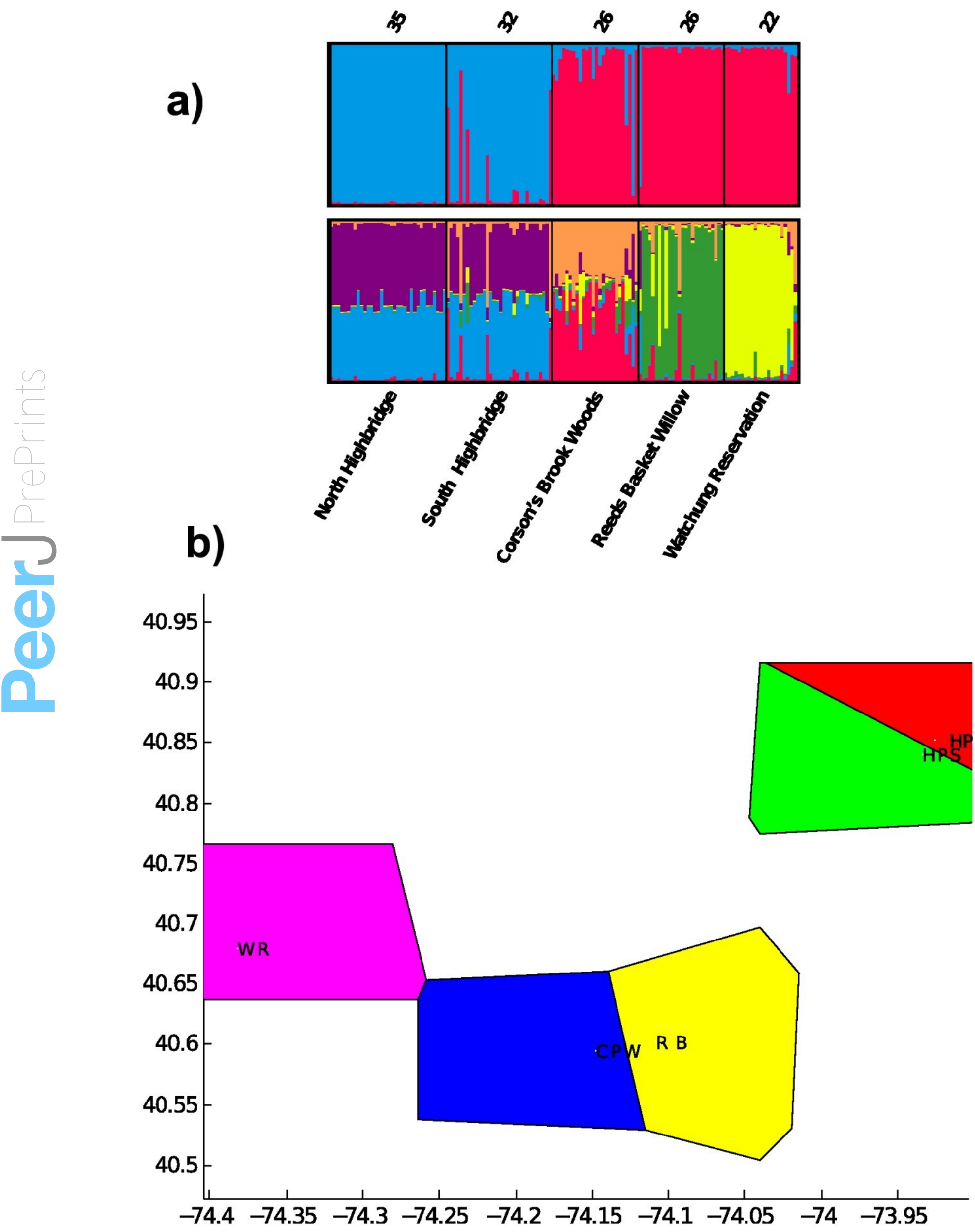


\section{Table $\mathbf{1}_{\text {(on next page) }}$}

Characteristics of five microsatellite loci genotyped in five NYC populations 
Table 1. Characteristics of five microsatellite loci genotyped in five NYC populations

\begin{tabular}{cccccccc}
\hline \multicolumn{7}{c}{ Allele size } & \\
Locus & range & $\mathrm{N}^{1}$ & $\mathrm{~N}_{\mathrm{A}}{ }^{2}$ & $\mathrm{~N}_{\mathrm{E}}{ }^{3}$ & $\mathrm{H}_{\mathrm{O}}{ }^{4}$ & $\mathrm{H}_{\mathrm{E}}{ }^{5}$ & $\mathrm{HWE}^{6}$ \\
\hline Dau3 $^{\mathrm{a}}$ & $124-268$ & 122 & 8 & 1.86 & 0.246 & 0.462 & $* * *$ \\
Dau11 $^{\mathrm{a}}$ & $275-319$ & 136 & 9 & 2.42 & 0.331 & 0.589 & $* * *$ \\
Dau12 $^{\mathrm{a}}$ & $273-405$ & 110 & 17 & 5.3 & 0.573 & 0.811 & $* * *$ \\
Doc03 $^{\mathrm{b}}$ & $153-185$ & 125 & 8 & 2.01 & 0.32 & 0.502 & $* * *$ \\
Ens6 $^{\mathrm{c}}$ & $120-188$ & 127 & 10 & 2.19 & 0.142 & 0.542 & $* * *$ \\
\hline${ }^{1}$ Number of individuals genotyped in five populations; $^{2}$ number of alleles; ${ }^{3}$ number of effective \\
alleles; ${ }^{4}$ observed heterozygosity; ${ }^{5}$ expected heterozygosity; ${ }^{6 * * *}$ significant deviation $(P<$ \\
0.0001) from Hardy-Weinberg equilibrium for entire dataset
\end{tabular}




\section{Table 2 (on next page)}

Genetic variation and bottlenecks among populations of northern dusky salamanders in NYC area. 
Table 2. Genetic variation and bottlenecks among populations of northern dusky salamanders in NYC area. Statistics were calculated both separately and combined for the north and south samples from Highbridge Park.

\begin{tabular}{lcccccccc}
\hline \multicolumn{1}{c}{ Site } & $\mathrm{N}^{1}$ & $\mathrm{~N}_{\mathrm{A}}{ }^{2}$ & $\mathrm{~N}_{\mathrm{E}}{ }^{3}$ & $\mathrm{~N}_{\mathrm{P}}{ }^{4}$ & $\mathrm{H}_{\mathrm{O}}{ }^{5}$ & $\mathrm{H}_{\mathrm{E}}{ }^{6}$ & $\mathrm{BN}^{7}$ & $\mathrm{HWE}^{8}$ \\
\hline Highbridge North & 32.4 & 2.4 & 1.24 & 1 & 0.143 & 0.151 & 0.016 & -- \\
Highbridge South & 29.0 & 5.2 & 1.65 & 11 & 0.288 & 0.293 & 0.031 & Dau11, Doc3, Ens6 \\
\hline Highbridge combined & 61.4 & 5.8 & 1.44 & 13 & 0.18 & 0.229 & 0.016 & Dau11, Doc3, Ens6 \\
\hline Corson's Brook Woods & 18.8 & 5.4 & 3.58 & 5 & 0.567 & 0.651 & 0.89 & Dau11, Ens6 \\
Reed's Basket Willow & 24.2 & 3.6 & 1.9 & 3 & 0.406 & 0.428 & 0.313 & Ens6 \\
Watchung Reservation & 19.6 & 4.0 & 2.15 & 5 & 0.398 & 0.425 & 0.031 & Dau3 \\
\hline${ }^{1}$ Average number of individuals genotyped at five loci; ${ }^{2}$ average number of alleles; ${ }^{3}$ average \\
number of effective alleles; ${ }^{4}$ number of private alleles; ${ }^{5}$ observed heterozygosity; ${ }^{6}$ expected \\
heterozygosity; ${ }^{7}$ P-value from bottleneck analysis; ${ }^{8}$ loci deviating significantly $(P<0.05)$ from \\
Hardy-Weinberg equilibrium
\end{tabular}




\section{Table 3 (on next page)}

Pairwise $F_{\text {ST }}$ calculated between five NYC populations (below diagonal). Values above diagonal are $P$-values calculated from 1,000 permutations of the data in GenAlex. 
Table 3. Pairwise $F_{\mathrm{ST}}$ calculated between five NYC populations (below diagonal). Values above diagonal are $P$-values calculated from 1,000 permutations of the data in GenAlex. HPN $=$ Highbridge Park North; HPS = Highbridge South; CBW = Corson’s Brook Woods; RB = Reed's Basket Willow; WR = Watchung Reservation

\begin{tabular}{cccccc}
\hline & HPN & HPS & CBW & RB & WR \\
\hline HPN & -- & 0.001 & 0.001 & 0.001 & 0.001 \\
HPS & 0.079 & -- & 0.001 & 0.001 & 0.001 \\
CBW & 0.388 & 0.275 & -- & 0.001 & 0.001 \\
RB & 0.514 & 0.409 & 0.242 & -- & 0.001 \\
WR & 0.490 & 0.386 & 0.213 & 0.218 & -- \\
\hline
\end{tabular}

